\title{
Determination of sex from the morphometry of orbits in adult skull of contemporary eastern Indian population
}

\author{
Naren Sarkar and Partha Pratim Mukhopadhyay
}

\begin{abstract}
Background: Determination of sex from the structure of orbits in the human skull is well documented. Both morphology and morphometry of the orbits have application in the determination of sex in skeletal remains. These parameters are often population-specific and warrant research on a regional basis. The present study was conducted to examine the sexual dimorphism of orbits in eastern Indian population. It was designed with the objective to determine the sex of the skull from the linear dimensions of orbits by deriving a specific multivariate function for classification.

Materials and methods: The investigation was conducted on a series of 92 human skulls (61 males and 31 females). The orbital height $(\mathrm{OH})$ and breadth $(\mathrm{OB})$ were measured by using digital vernier calliper. Data analysis was performed by computing descriptive statistics like mean, standard deviation and range. Linear discriminant function analysis was carried out to derive a classification model.

Results: It was noted that the orbital dimensions were more in females than in males. A multivariate function was derived from the discriminant function analysis. The estimated sectioning point or cut off score was calculated to be -0 . 141. If the score of the function was more than -0.141 , then sex can be assigned as male. On the other hand, if it was less than -0.141 , then it was female. Likewise, sex could be correctly assigned in $68.5 \%$ of the cases by this method.

Conclusion: This study provides useful baseline orbital morphometric data for East Indian population. When applied in sex determination, this multivariate model returns $68.5 \%$ correct classification. It will be useful and easy populationspecific method of sex determination from human skulls. This morphometric data can be used in further forensic research involving identification from skeletal remains.
\end{abstract}

Keywords: Forensic anthropology, Sex determination, Discriminant function analysis, Adult dry skull, Digital vernier calliper, Orbital dimensions, Eastern Indian population

\section{Background}

Methods of determination of sex from skeletal remains have been an area of continued research in forensic anthropology. The orbit is an important anatomic landmark in the skull. The orbital measurements are one of the craniofacial variables that have been successfully applied in anthropological work for human identification. Several circumstances like exploration of mass graves, war victims, homicidal dismemberment, mutilation and natural disaster may necessitate the use of anthropometry to identify the sex of a person from the available

\footnotetext{
* Correspondence: drpartha99md@gmail.com

Department of Forensic and State Medicine, Burdwan Medical College, Purba Bardhhaman, WB 713104, India
}

skeletal remains. Orbital height and breadth are useful for identification, sex determination and demic allocation in anthropology. Orbital measurements can be used to create a new data collection for a given population (Birkby 1966; Baughan and Demirjian 1978; Franklin et al. 2005; Kaya et al. 2014). The morphology of the orbit has been used to differentiate between male and female skull (Calcagno 1981; Buikstra and Ubelaker 1994; Bruzek and Murail 2006; Biswas et al. 2015). Earlier works have also revealed pragmatic application of morphometry of orbits in the determination of sex in South African (Dayal et al. 2008), Balkan (Đurić et al. 2005) and Indian (Jain et al. 2016) skulls. The present study was designed to estimate sexual dimorphism and determine 
sex with the help of metric dimensions of orbit in adult skulls of the contemporary eastern Indian population.

\section{Materials and methods}

The present research was conducted in the Department of Forensic and State Medicine of Burdwan Medical College, Burdwan, West Bengal, India. The bones were collected from the archives of the departmental museums of two medical colleges of eastern India. The skulls belonged to the population of the province of West Bengal, a populated region of eastern India with primarily Indo-Aryan race among others. The morphometric study was done on 92 skulls (61 males and 31 females). The skulls were dry and fully ossified. None of the skulls had any injury, congenital deformity or artefacts. The orbits were measured twice in two different days by a single researcher after putting the skull in Frankfurt's horizontal plane. The orbital height and breadth was measured by digital vernier calliper up to the nearest millimetre $(\mathrm{mm})$.To test for inter-observer agreement rating of the method, 20 randomly chosen bones were measured by two observers and the results were tested by Cohen's kappa statistics. For intra-observer reliability, the two set of measurements were compared by paired $t$ test wherein no significant difference was found in the mean values. The data was analysed using the SPSS version 19.0 computer software for descriptive and inferential statistics. Computing of descriptive statistics was followed by discriminant function analysis (DFA). A $p$ value of less than .05 was used for statistical significance

\section{Measurement of orbital parameters}

Parameters of bony orbits measured in millimetres according to the methods of Buikstra and Ubelaker 1994.

A-B: orbit height $(\mathrm{OH})$; C-D: orbit breadth (OB) (Fig. 1).

Ectochion-the intersection of the most anterior surface of the lateral border of the orbit and a line bisecting the orbit along its long axis.

Dacryon-the point on the medial border of the orbit at which the frontal, lachrymal and maxilla bones intersect.

Orbit breadth $(\mathrm{OB})$ - the distance in millimetres between the dacryon and ectochion was measured as the orbital breadth (Fig. 2).

Orbit height $(\mathrm{OH})$ - the direct distance in millimetres between the superior and inferior orbital margins perpendicular to the orbital breadth (Fig. 3).

\section{Results}

The present study was conducted on a sample composed of 92 adult skulls. Of these, 61were males and $31 \mathrm{fe}$ males. The age of the sample ranged from 25 to 60 years. The mean and standard deviation of the independent variables are shown in Table 1.

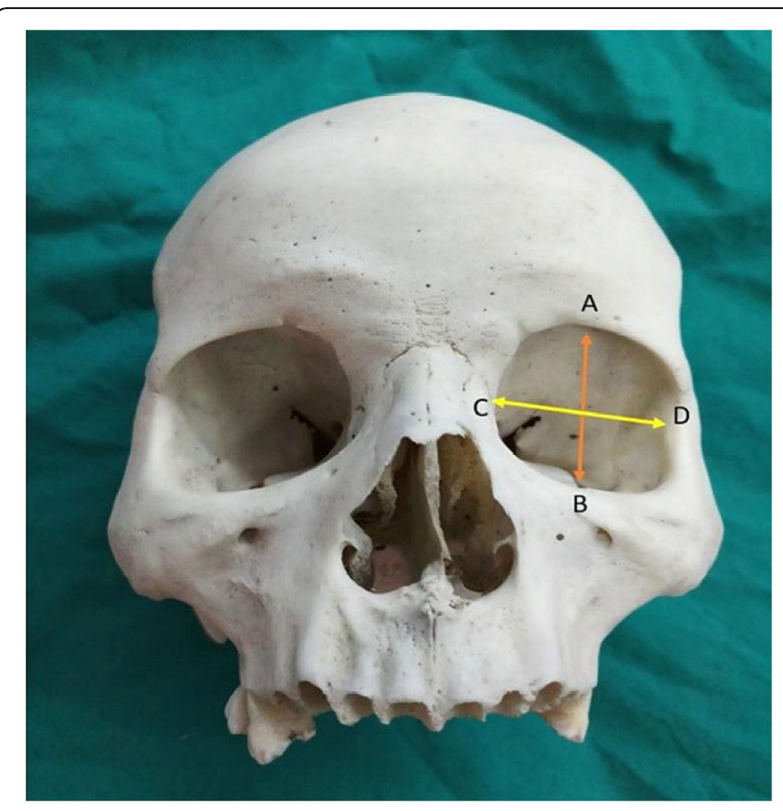

Fig. 1 The measurements used in the study. $A-B$ : orbit height $(\mathrm{OH})$; C-D: orbit breadth $(\mathrm{OB})$

Group statistics of orbital parameters in respect of male and female was shown in Table 2.

There were no significant differences in height and breadth between the orbit of the right and left side. A direct discriminant function analysis was performed using four variables as predictors of sex, and all the variables were entered together. The classification groups were male and female. One discriminant function was calculated with Wilks' Lambda equal to 0.854 , chi-square $\left(\chi^{2}\right)$

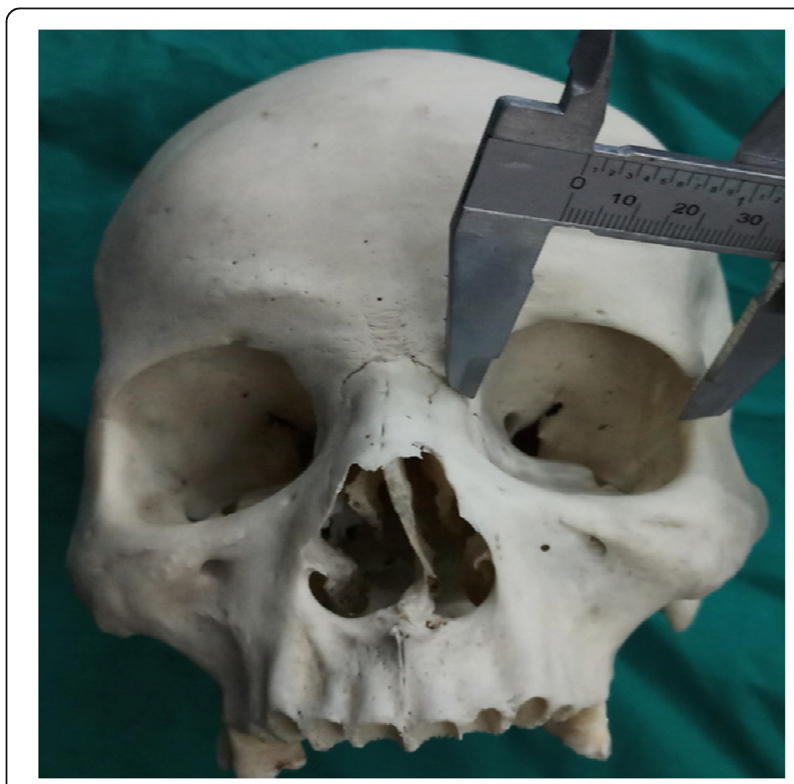

Fig. 2 The measurement of orbit breadth $(O B)$ : the distance between the dacryon and ectochion as the orbital breadth 


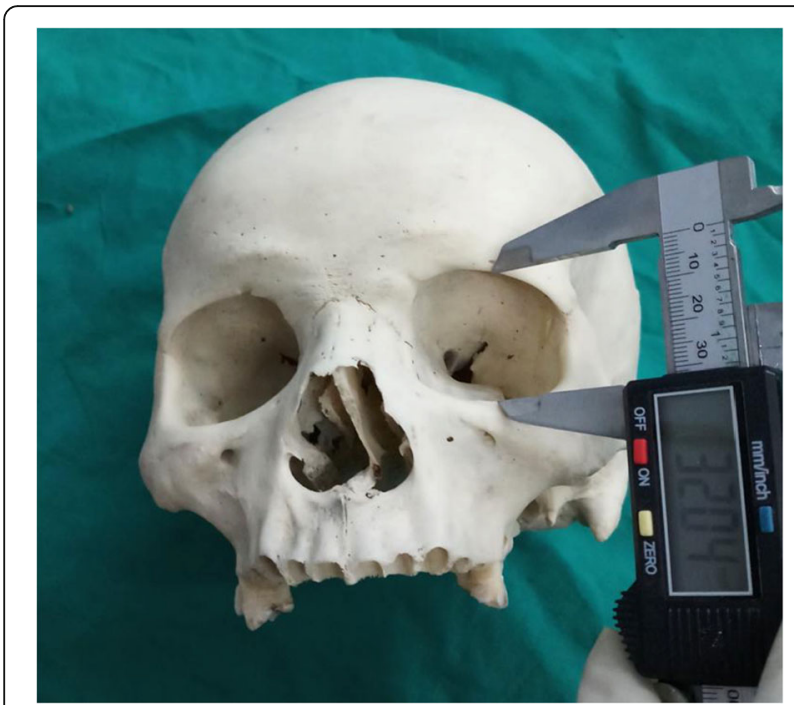

Fig. 3 The measurement of orbit height $(\mathrm{OH})$ : the direct distance between the superior and inferior orbital margins perpendicular to the orbital breadth

equal to 13.915, a degree of freedom 4 and a $P$ value of.008. Because the $P$ value was less than .05 , we could say that the model was a good fit for the data (Table 3).

Discriminant function analysis (DFA) was conducted, and the following function was obtained: $\mathrm{DF}=0.579$ $\mathrm{ROB}-0.268 \mathrm{ROH}-0.302 \mathrm{LOH}-0.004 \mathrm{LOB}-2.623$.

Sexual dimorphism was analysed in the model using a discriminant function. The standardised canonical coefficients and the structure weights reveal that the four variables contributed to the multivariate effect (Table 4).

The cut score was - 0. 141 [calculated from group centroid (Table 5) by obtaining the arithmetic mean of the values].

In those cases where the DF score was less than 0.141 , the skull was female, and a value of discriminant score above -0.141 was male. By applying this method, only $68.5 \%$ of the cases were correctly classified by the model (Table 6). The matrix scatter plot (Fig. 4) shows the scatter of the possible combination of the variables that help differentiate between the two groups.

\section{Discussion}

It is well established that cranial morphometry significantly differs among populations (Birkby 1966; Baughan and Demirjian 1978; Franklin et al. 2005; Kaya et al. 2014).
Table 2 Group statistics

\begin{tabular}{llll}
\hline Sex & & Mean & Standard deviation \\
\hline Male & ROH & 34.9680 & 3.85658 \\
& ROB & 39.8677 & 4.05540 \\
& LOH & 35.2230 & 3.83537 \\
Female & LOB & 39.9323 & 3.97298 \\
& ROH & 35.6326 & 5.16685 \\
& ROB & 39.0094 & 4.91980 \\
& LOH & 35.8648 & 5.32614 \\
Total & LOB & 39.1706 & 4.91690 \\
& ROH & 35.1920 & 4.32519 \\
& ROB & 39.5785 & 4.35771 \\
& LOH & 35.4392 & 4.37539 \\
& LOB & 39.6757 & 4.30215 \\
\hline
\end{tabular}

The present analysis was undertaken on a sample of 68 skulls of eastern Indian origin. The skulls belonged to the population of the province of West Bengal, a populated region of eastern India with primarily Indo-Aryan race among others.

Earlier works on Indian Bengali population has shown that human orbits exhibit asymmetry (Biswas et al. 2015). In the present series, there was significant asymmetry in the orbital dimensions. So, we considered taking all the measurements of both sides in our analysis. Discriminant function analysis was used to determine which continuous variables discriminate between two or more naturally occurring groups. In this study, the method of discriminant function analysis was used to evaluate how a linear combination of those four variables can discriminate between male and female skulls. DFA has been successfully used to determine sex in Indian Bengali samples of the sternum, hyoid, hip and clavicle (Mukhopadhyay 2010; Mukhopadhyay 2012a, b, c; Sarkar and Mukhopadhyay 2015). Morphological assessment for sex determination(Birkby 1966; Calcagno 1981; Buikstra and Ubelaker 1994; Bruzek and Murail 2006) has been reported earlier with reasonable success. However, in forensic cases, discriminant function analysis is preferred as it is less subjective and can be easily worked out.

The analysis showed that this model could correctly classify overall $68.5 \%$ of original grouped cases. This result in the population-specific sample (eastern Indian population) is better than other studies in India (Jain et

Table 1 Descriptive statistics

\begin{tabular}{lllllll}
\hline Table-1 & $N$ & Range & Minimum & Maximum & Mean & Standard deviation \\
\hline ROH & 92 & 17.69 & 28.78 & 46.47 & 35.1920 & 4.32519 \\
ROB & 92 & 19.37 & 31.86 & 51.23 & 39.5785 & 4.35771 \\
LOH & 92 & 18.74 & 28.15 & 46.89 & 35.4392 & 4.37539 \\
LOB & 92 & 18.82 & 32.36 & 51.18 & 39.6757 & 4.30215 \\
\hline
\end{tabular}


Table 3 The Wilks' lambda and related statistics

\begin{tabular}{|c|c|c|c|c|}
\hline \multicolumn{5}{|l|}{ Eigenvalues } \\
\hline Function & Eigenvalue & $\%$ variance & Cumulative \% & $\begin{array}{l}\text { Canonical } \\
\text { correlation }\end{array}$ \\
\hline 1 & .171 & 100 & 100 & .382 \\
\hline \multicolumn{5}{|c|}{ First canonical discriminant functions were used in the analysis. } \\
\hline \multicolumn{5}{|l|}{ Wilks' lambda } \\
\hline Test of function(s) & $\begin{array}{l}\text { Wilks' } \\
\text { lambda }\end{array}$ & Chi-square & $\begin{array}{l}\text { Degree of } \\
\text { freedom(df) }\end{array}$ & Sig. \\
\hline 1 & .854 & 13.915 & 4 & .008 \\
\hline
\end{tabular}

al. 2016) where correct classification was possible using the different predictors. The modest $68.5 \%$ accuracy of the present series is comparable with the results of another recent work using CT on Turkish population (Kaya et al. 2014). The present results are however less accurate than an earlier study (Dayal et al. 2008) where 120 skulls, 60 males and 60 females, were used in Black South African sample leading to $85 \%$ correct classification of sex. Our contention is that morphometry and sexual dimorphism in adult human orbits can be applied for the analysis of human remains on a regional basis. Discriminant functions too are population-specific which prompted the present investigation. This is in concurrence with earlier works (Dayal et al. 2008; Jain et al. 2016; Mukhopadhyay 2010; Cunha and van Vark 1991). This would have anthropological, archaeological and forensic applications especially in cases of determination of sex of unknown mutilated or grossly decomposed body. The sex-related changes in the orbital dimensions are a well-documented factor that needs to be considered in future studies. To the best of our knowledge and extensive literature reviews, this is perhaps the only work on orbital measurement and sex determinations in eastern Indian population. We make no pretence of finality. This is a pilot study that was aimed to explore the possibility of sexing the human skull using orbital measurements in a given population. The study was on a sample of only 92 human skulls. Linear measurements were taken for the variables. The present work was conducted with osteometric analysis of only four variables obtained from the human orbits. Further research with a larger study sample and a

Table 4 Canonical discriminant function coefficients

\begin{tabular}{ll}
\hline & Function \\
\hline $\mathrm{ROH}$ & 1 \\
$\mathrm{ROB}$ & -.268 \\
$\mathrm{LOH}$ & .579 \\
$\mathrm{LOB}$ & -.302 \\
(CONSTANT) & -.004 \\
\hline
\end{tabular}

Table 5 Functions at group centroids

\begin{tabular}{lll}
\hline Sex & Function & $\begin{array}{l}\text { Cutoff score } \\
\text { Male }+ \text { female/2 }\end{array}$ \\
\hline Male & 1 & -0.141 \\
Female & .292 & \\
\hline
\end{tabular}

greater number of measurable variables should be performed to discriminate between male and female orbits. The results of this preliminary study show that these four variables contribute to discrimination between the two sexes in the eastern Indian population. This approach can also be applied to supplement sex determination methods with different bones like sternum, hyoid, hip and clavicle (Mukhopadhyay 2010; Mukhopadhyay 2012a, b, c; Sarkar and Mukhopadhyay 2015) in eastern Indian skeletal remains. This method will be of practical use in forensic research when cranial as well as postcranial remains are examined for human identification.

\section{Conclusion}

Discriminant function analysis (DFA) is a helpful technique for determination of sex from orbits of the human skull. The orbit of eastern Indian population is sexually dimorphic. This was observed using parameters like orbital height and breadth. Discriminant function equations have been derived from various combinations of these measurements. It is possible to determine the sex of the skull from the orbital dimensions with acceptably high average accuracy. Numerous previous studies have shown that discriminant function equations are population-specific. It is suggested that the equation derived from the present study should be applied only to the eastern Indian population group. We intend to improve our data set by including more individual bones for each age and sex class. Our method will also be tested in other populations to derive the percentage of accurate classification. We recommend

Table 6 The summary of classification results

\begin{tabular}{|c|c|c|c|c|c|}
\hline & & \multirow[t]{2}{*}{ Sex } & \multicolumn{2}{|c|}{$\begin{array}{l}\text { Predicted group } \\
\text { membership }\end{array}$} & \multirow{2}{*}{$\begin{array}{l}\text { Total } \\
\text { Male }\end{array}$} \\
\hline & & & Male & Female & \\
\hline \multirow[t]{4}{*}{ Original } & Count & Male & 42 & 19 & 61 \\
\hline & & Female & 10 & 21 & 31 \\
\hline & $\%$ & Male & 68.9 & 31.1 & 100 \\
\hline & & Female & 32.3 & 67.7 & 100 \\
\hline \multirow[t]{4}{*}{ Cross-validated (a) } & Count & Male & 40 & 21 & 61 \\
\hline & & Female & 10 & 21 & 31 \\
\hline & $\%$ & Male & 65.6 & 34.4 & 100 \\
\hline & & Female & 32.3 & 67.7 & 100 \\
\hline
\end{tabular}

(a) Cross-validation is done only for those cases in the analysis In cross-validation, each case is classified by the function derived from all cases other than that case $68.5 \%$ of original grouped cases correctly classified $66.3 \%$ of cross-validated grouped cases correctly classified 


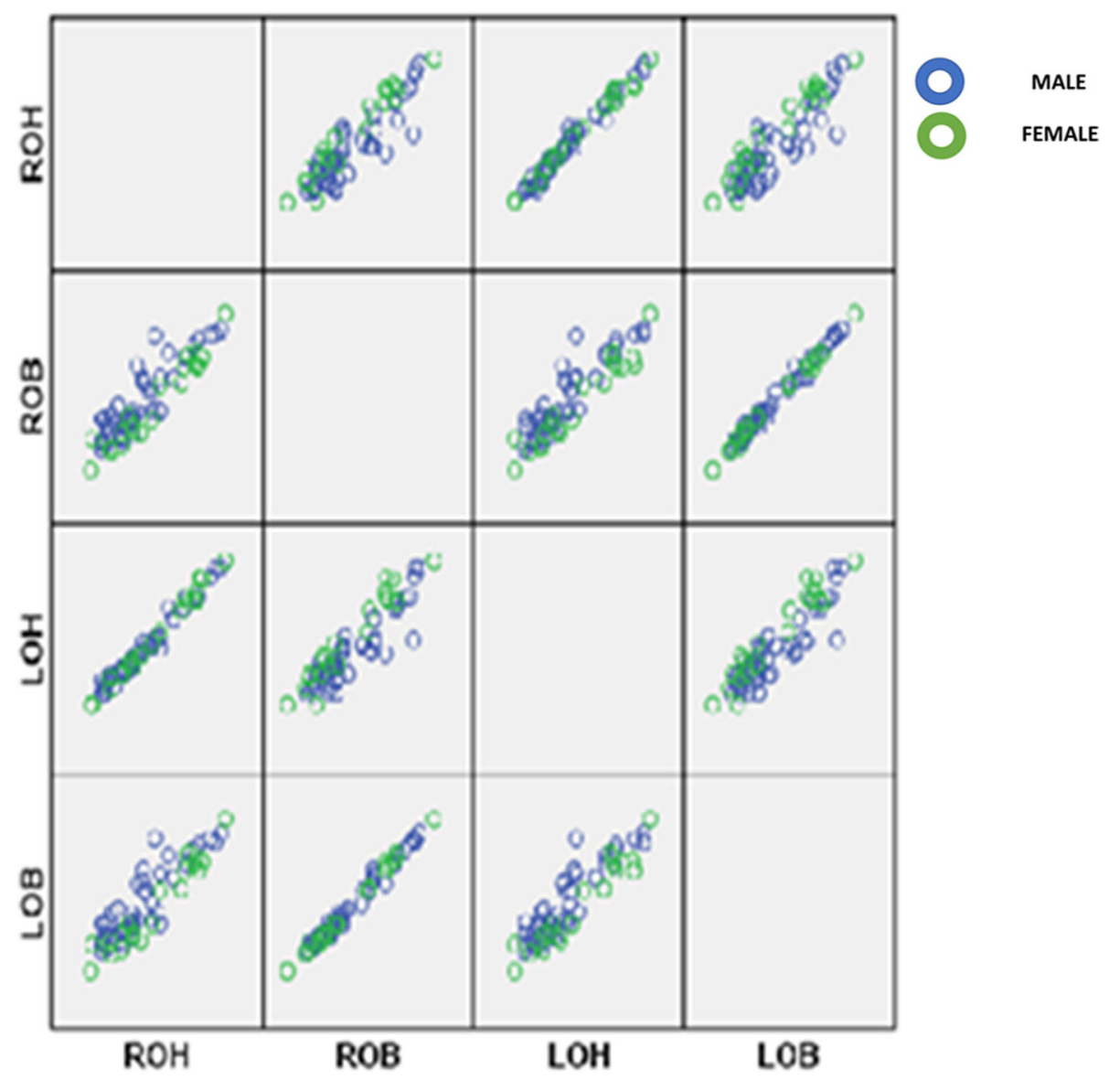

Fig. 4 The scatter matrix plot of the variables used to predict sex. (ROH right orbital height, ROB right orbital breadth, LOH left orbital height, LOB left orbital breadth. Blue dots indicate male. Green dots indicate female scale type linear)

working with newer methods like geometric morphometrics (Bytheway and Ross 2010; Corner et al. 1992) on orbits belonging to the Indian population. The results of the present study can be utilised in forensic anthropology and bioarchaeology. Multicentre collaborative works can lead to the creation of software like Fordisc ${ }^{\oplus}$ for the Indian population.

\section{Abbreviations}

DF: Discriminant function; DFA: Discriminant function analysis; LOB: Left orbital breadth; LOH: Left orbital height; OB: Orbital breadth; OH: Orbital height; ROB: Right orbital breadth; $\mathrm{ROH}$ : Right orbital height

\section{Acknowledgements}

The authors would like to acknowledge the contribution of Dr. Arani Majumdar, Demonstrator, and Dr. Koushik Roy, MD postgraduate trainee, forensic medicine, Burdwan Medical College, Burdwan, WB, India. We thank Dr. Achintya Biswas, Assistant Professor, Forensic Medicine, Dr. Soumeek Chowdhury, Tutor, Forensic Medicine CNMC Kolkata and the Head of the Department of Anatomy CNMC Kolkata-14, WB, India, for their kind permission to access the museum samples. We would also like to thank the reviewers for their valuable suggestions and inputs during the process of blind peer review.

\section{Funding}

Not applicable

No funding for the present cases from any sources. All are done as part of routine academic work.
Availability of data and materials

Archives of the departmental museum

\section{Authors' contributions}

NS collected the samples from archives of the departmental museum and measured all adult skulls of known sexes with digital vernier calliper twice on different days. The data were obtained, tabulated and analysed statistically under the supervision and guidance of the H.O.D, Professor (Dr.) PPM of Forensic Medicine, Burdwan Medical College. Review of literature was done by NS. The manuscript was written by NS. Review and correction were done by both of the authors. The entire work was planned, conceptualised and analysed by professor PPM. The manuscript was read and approved by both of the authors.

\section{Authors' information}

Dr. Naren Sarkar is a postgraduate student of Forensic Medicine at Burdwan Medical College, Bardhaman, West Bengal India. Professor (Dr) Partha Pratim Mukhopadhyay is the Head of the Department of Forensic Medicine at Burdwan Medical College, Bardhaman, West Bengal India.

\section{Ethics approval and consent to participate}

Full ethics approval and clearance was approved. The consent is not required for the data collection as the adult dry skulls were collected from the archives of the departmental museum, only written permission was taken from the Heads of the Department of Forensic Medicine and Anatomy of two teaching institutions as per protocol.

\section{Consent for publication}

Not applicable 


\section{Competing interests}

The authors declare that they have no competing interests.

\section{Publisher's Note}

Springer Nature remains neutral with regard to jurisdictional claims in published maps and institutional affiliations.

Received: 20 February 2018 Accepted: 28 October 2018

\section{Published online: 13 November 2018}

\section{References}

Baughan B, Demirjian A (1978) Sexual dimorphism in the growth of the cranium. Am J Phys Anthropol 49:383-390

Birkby WH (1966) An evaluation of race and sex identification from cranial measurements. Am J Phys Anthropol 24:21-28

Biswas S, Chowdhuri S, Das A, Mukhopadhyay PP (2015) Observations on symmetry and sexual dimorphism from morphometrics of foramen magnum and orbits in adult Bengali population. J Indian Acad Forensic Med OctoberDecember 37(4):52-56

Bruzek J, Murail P (2006) Methodology and reliability of sex determination from the skeleton. In: Schmitt A, Cunha E, Pinheiro J (eds) ForensicAnthropology and medicine. Humana Press, Totowa, pp 225-242

Buikstra JE, Ubelaker DH (1994) Standards: for data collection from human skeletal remains. Arkansas Archaeological Survey series, Fayetteville, p 44

Bytheway JA, Ross AH (2010) A geometric morphometric approach to sex determination of the human adult OS coxa. J Forensic Sci 55(4):859-864

Calcagno JM (1981) On the applicability of sexing human skeletal material by discriminant function analysis. J Hum Evol 10:189-198

Corner BD, Lele S, Richtsmeier JT (1992) Measuring precision of threedimensional landmark data. J Quant Anthropol 3:347-359

Cunha E, van Vark GN (1991) The construction of sex discriminant functions from a large collection of skulls of known sex. Int J Anthropol 6(1):53-66

Dayal MR, Spocter MA, Bidmos MA (2008) An assessment of sex using the skull of black South Africans by discriminant function analysis. HOMO 59:209-221

Đurić M, Rakočević Z, Đonić D (2005) The reliability of sex determination of skeletons from forensic context in the Balkans. Forensic Sci Int 147:159-164

Franklin D, Freedman L, Milne N (2005) Sexual dimorphism and discriminant function sexing in indigenous South African crania. HOMO 55:213-228

Jain D, Jasuja OP, Nath S (2016) An assessment of sex using craniofacial measurements of human crania by discriminant function analysis. Rom J Leg Med 24(4):294-299

Kaya A, Uygun S, Eraslan C, Akar GC, Kocak A, Aktas E, Govsa F (2014) Sex estimation: 3D CTA-scan based on orbital measurements in Turkish population. Rom J Leg Med 22(4):257-262

Mukhopadhyay PP (2010) Determination of sex from adult sternum by discriminant function analysis on autopsy sample of Indian Bengali population: a new approach. J Indian Acad Forensic Med 32(4):321-323

Mukhopadhyay PP (2012a) Determination of sex by sciatic notch/acetabular ratio (Kelley's Index) in Indian Bengali skeletal remains. J Indian Acad Forensic Med 34(1):27-30

Mukhopadhyay PP (2012b) Determination of sex from an autopsy sample of adult hyoid bones. Med Sci Law 52(3):152-155

Mukhopadhyay PP (2012c) Determination of sex from fragment of hipbone in. Indian Bengali J Indian Acad Forensic Med 34(4):309-311

Sarkar NR, Mukhopadhyay PP (2015) Sex determination from clavicular length and mid-shaft diameter using digital X-ray in Indian Bengali population: a preliminary study. Indian J Forensic Med Toxicol 9(2):148-153

\section{Submit your manuscript to a SpringerOpen ${ }^{\circ}$ journal and benefit from:}

- Convenient online submission

- Rigorous peer review

- Open access: articles freely available online

- High visibility within the field

- Retaining the copyright to your article

Submit your next manuscript at $\boldsymbol{\nabla}$ springeropen.com 